\title{
Palabras del Dr. Héctor Samour en la presentación del libro ILOBASCO de los recuerdos. De las muchas cosas que pasaban, del Dr. Ramón Rivas. San Salvador (19/03/2014)
}

Héctor Samour

Catedrático, investigador Exministro de Educación

Dr. Ramón Rivas: muchas gracias por este magnífico libro que hoy lanza al espacio público y por la deferencia de seleccionarme para hacer su presentación en una ocasión irrepetible. Gracias no solo de mi persona, sino, también, de parte de los innumerables lectores que se beneficiarán y sorprenderán con la armoniosa articulación que usted ha logrado con los variados e incontables esfuerzos académicos y de investigación aquí concentrados.

Nos muestra maestría al presentarnos, en una forma muy sencilla, como sin esfuerzos, salida de un flujo natural de ideas, atrás de una taza de café o en una conversación de amigos, el arduo, largo y, a veces, tedioso trabajo de la labor del investigador serio, tales como la definición del problema o los problemas que se tenían que tratar, la delimitación de los tiempos que se debían visualizar, la identificación del sujeto de la investigación, la metodología que habría de emplear, cuales son los actores o sistemas que se estudiarían, el trabajo de campo, las entrevistas, la repetición de las entrevistas, la verificación de la información o conclusiones, la recolección y sistematización de datos, su procesamiento, la búsqueda de la coherencia interna del informe y la selección de las mejores formas de la exposición de resultados.

A estas laboriosas tareas se agregan los trabajos para la publicación del libro, es decir, pasar por los exigentes procesos arbitrados que las universidades y/o casas editoras hacen para garantizar la calidad de sus publicaciones, las sesiones para adecuar lo escrito con los requerimientos editoriales o consejos del editor, los cálculos presupuestarios y todo el proceso de taller técnico de la producción del libro.

Gracias por tan armonioso resultado, que hoy vemos sale a buscar a los lectores y las opiniones que son de una gran variedad en nuestro medio cultural e intelectual. 
Unas palabras más sobre la fase de edición. Sin lugar a dudas, es una edición muy cuidada, un proyecto editorial esmerado en su concepción, diseño, diagramación, edición, impresión, encuadernación y empastado.

El color de las pastas, de las fotografías, de los títulos y subtítulos, de los pies de fotografía, prestan al libro, con esa diversidad de "sepias", un aíre del "pasado", de "lo que fue" pero que ha quedado en nuestra identidad actual, en nuestro "subconsciente", en nuestros "genes" culturales, condicionando nuestra identidad actual. Identidad con retazos de cultura local, comunal y familiar, tal como nos lo cuentan la abuela, los viejos sabios del pueblo, los que lo oyeron de sus mayores y que nos lo cuentan en las esquinas del barrio (¿o también ya "pasaron”, Ramón?), y que adquieren vida en nuestro diario vivir.

Felicitaciones a la editorial de la Universidad Tecnológica de El Salvador y a sus especialistas en esta pequeña y grande obra de editar y publicar un libro con calidad, habilidad artística y utilizando las imprescindibles TIC. El autor también tiene parte en estas magníficas decisiones en la edición de su libro.

¿Y de qué trata de convencernos, de qué quiere que dialoguemos, de qué trata el libro de Ramón Rivas?

Una impresión inicial que tuve en la lectura del libro es que Ramón Rivas había elaborado una etnología de "lo ausente", con la que trata de retener "lo que fue", "lo que está por desaparecer ante nuestros ojos y ante nuestra actitud de incapacidad por mantener actualizado el pasado que se diluye como agua — no quiero decir arena - de nuestras manos".

Una etnografía de lo perdido, pero que aún está con nosotros como una huella indeleble en nuestra vida individual; que tiene un fin real, pero también en la vida colectiva; que tiene una duración indecible, y que es ahí donde perdura "lo que ocurre".

Es una mezcla transdisciplinaria difícil. La casa editora la clasifica en su portada entre la antropología y la historia. En efecto, ILOBASCO —el libro - tiene una dimensión de la antropología, si la pensamos como un término general, para una serie de estudios que incluyen etnología, etnografía, antropología social y cultural, estudios de folclore y otros. Durante la lectura recordé que la reciente definición de antropología de David Schneider como el estudio de la cultura definida como un sistema de símbolos y significados, que tienen que ver con "las formas de vida", es una buena y relativa sinopsis de lo que Rivas nos muestra en su libro. Pero es un sistema de símbolos y significados que, estando aun presente en la realidad de una ciudad actual, está también "pasando" y ha dejado de ser "lo que era".

Es historia, por supuesto, pero de una "historia del presente". Rivas retoma desde nuestra actualidad, desde El Salvador en que por primera vez gana las elecciones un partido de izquierdas con representantes militantes - digo- Rivas retoma "aquellas cosas que 
pasaban" y las persigue desde sus inicios, desde aquel "pueblo de indios" (término peyorativo de los colonizadores) que llegó a ser luego "San Miguel de Xilobasco o Hilobasco", situado en la región de San Vicente de Austria y Lorenzana, hasta su existencia como la actual ciudad de Ilobasco.

Es muy difícil atrapar la producción que hoy comentamos en una sola de estas disciplinas, pues podría ubicarse también, sin desmérito alguno, en el campo de la literatura, por lo bien narrado que está y por la maestría de la narración de bellísimas realidades, en las que se requiere creatividad, dominio del lenguaje y capacidad de profundizar en el alma de los personajes, en este caso, una comunidad en cambio con una infinidad de personajes que le dieron "alma y vida" a ese período en el que se centra, que va desde la primera década hasta los 50 o 60 del siglo XX.

Podría situarse, por otra parte, en el género de las "memorias", pues, aunque no es un recuento sobre sus experiencias en el campo de sus decisiones íntimas frente a momentos definitorios para su persona, lo descrito es parte de la vida de Ramón, que queda pincelada en estos 54 cuadros o "unidades de observación o análisis" en que nos sitúa el estudio de $I L O B A S C O . .$. , que recuerdan la escuela "impresionista" ante los paisajes que fueron y ya no son.

Hay una parte que nos mueve a pensar lo autobiográfico o memoria de esta obra. Rivas nos dice que en la comunidad de Ilobasco la gente se ha caracterizado por ser "gente activa y laboriosa". Eso sí, "metidos en todo". Por eso les llamaban los "pirres". Acto seguido, nuestro amigo Ramón nos confiesa que nació y creció en el mero barrio de los pirres. Nos dice sin ambages:

Allí crecí y llegué a conocer de memoria su color, las manchas de las paredes de sus casas, los cercos de piedra, los piñales y hasta los patios de las viviendas, así como también los hoyos peligrosos en los andenes rotos; y hasta reconocer que doña Lidia Nerio, frente a la plaza de la entonces ermita de El Calvario, disponía de la mejor tienda en donde se podía comprar de todo; desde cuajada, manteca de cuche, huevos por unidad o por docena, maiz, frijoles, arroz y maicillo libreado y por cuartillos y hasta por medios; y también que en una de las primeras refrigeradoras que llegaron al pueblo, toda una novedad en ese entonces, se guardaba para ofrecer al público bien heladas las chibolas, los topoyiyos y los bolis de todo sabor.

En verdad, Rivas nos ha regalado un libro extraordinario con un título impresionante por su exactitud y coherencia con la materia académica desarrollada. El libro lo titula el autor: ILOBASCO de los recuerdos. De las muchas cosas que pasaban.

"Pasar" es un verbo con diferentes acepciones. Pasar es "ocurrir", "suceder". "Pasar" es también "transitar" o "deslizarse", ¿“desvanerse"? Rivas — creo- se refiere a esos dos, o quizás más, significados. Me recuerda una poesía que nos recuerda el paso del tiempo en nuestras vidas. Se trata de aquella poesía de Antonio Machado: 
"Todo pasa y todo queda, pero lo nuestro es pasar, pasar haciendo caminos, caminos sobre la mar."

O la otra estrofa:

"Al andar se hace camino y al volver la vista atrás se ve la senda que nunca se ha de volver a pisar."

Decía que al inicio de la lectura tuve la sensación de que estaba ante una etnología de la ausencia. Los mismos títulos de los 54 focos de atención del autor nos reforzaban esta impresión. Son títulos sumamente atractivos y muy añorantes. Solo quiero mencionar unos ejemplos (hay que comprar y leer el libro):

- De lo que queda de las ventas de jarcia

- De doña Tránsito y su automóvil, que fue el primero que circuló en el creciente pueblo

- Del arribo de los turcos (palestinos, nos aclara después el Dr. Rivas)

- De cuando llegaban los húngaros

- De aquellos dorados años que el viento se llevó

- De cuando la patrulla reclutaba para la platada

- De la "calle de los bolos" y la cantina El Tenampa

Al finalizar el libro creo haber comprendido que el verdadero sujeto del libro, la verdadera búsqueda de Ramón Rivas, es el "cambio social", el "cambio cultural" que ocurre en nuestras comunidades y que se hace sobre nuestras cabezas, sobre nuestras formas de vida, sobre nuestros valores y costumbres, sobre nuestras maneras de ganarnos la vida, sobre las formas productivas y de pensar, y lo hace de una manera inmisericorde y sin que, a veces, comprendamos estos cambios en toda su magnitud y significación; y sin sentirlo, sin poder explicarlo...

Daré un solo ejemplo, por el tiempo ya transcurrido en esta presentación, de cómo impacta el paso del tiempo, los cambios tecnológicos, los cambios administrativos en nuestra vida cotidiana y nos impacta. En una de las unidades de recuerdo titulada "De las aventuras de Lázaro con la fotografía”, Rivas nos cuenta las experiencias de Lázaro en un párrafo:

Nunca pienso usar cámaras digitales. Nunca. Los fotógrafos profesionales no debemos usar eso. Eso se llama fraude a la profesión. Los profesionales como yo hacemos la foto y la revelamos en nuestro propio cuarto oscuro, usando químicos, papel de fotografia, revelador y fijador y el lápiz para retocar los negativos [...] Por mis cámaras han pasado los diferentes personajes alcaldes y sus personajes; presidentes como [...] pero la foto que yo considero más importante es la de Juan Pablo II, en su primera visita a El Salvador. 
En otro párrafo, Lázaro continúa:

Sigo tomando fotos porque me gusta, pero el negocio ahora es malo. Con las fotos de estudios tradicionales hoy estamos en quiebra. El Gobierno dio el trabajo a la empresa privada; y asi estamos hoy, todas las fotos para licencias, DUI y para lo que sea, las hacen empresas privadas. El Gobierno nos llevó a la quiebra.

Sin comentarios, Rivas nos presenta como se vuelve "ausente" una actividad que por muchos años tuvo un apogeo con cierta tecnología y ciertos mercados que al cambiar dejan atrás a quienes se mantienen tratando de mantener el "cómo se hacía antes"; y la ausencia, la desaparición, van ganando terreno. "Las cosas pasan", aunque por un tiempo mayor muchos de esos valores y comportamientos se mantienen en la gente y en los recuerdos de un mundo que ha seguido su marcha implacable e indetenible.

Gracias... Ramón.

Gracias, a ustedes.

Interesante: el autor hace renacer con sus recuerdos y los de la comunidad con los que hace este ejercicio de "memoria histórica" o de "memoria cultural". 


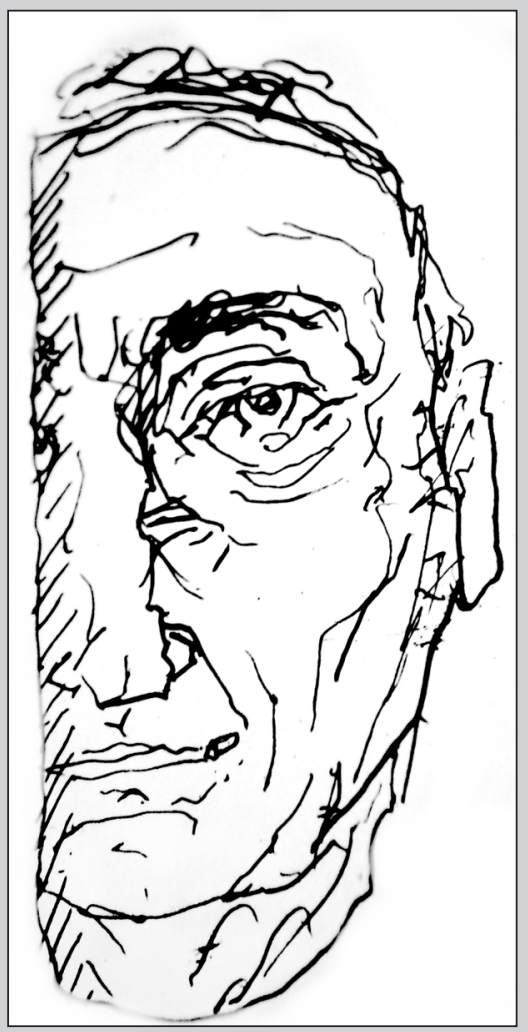

